\title{
FORMULATION AND EVALUATION OF ETHAMBUTOL POLYMERIC NANOPARTICLES
}

\author{
MONOWAR HUSSAIN ${ }^{*}$, ANUPAM SARMA², SHEIKH SOFIUR RAHMAN ${ }^{3}$, ABDUL MATIN SIDDIQUE ${ }^{4}$, TANUKU \\ PAVANI EESWARI ${ }^{5}$
}

${ }^{1 *}$ Department of Pharmaceutical Sciences, Dibrugarh University, Dibrugarh, Assam 786004, ${ }^{2}$ Pratiksha Institute of Pharmaceutical Sciences, Guwahati, Assam 781026, ${ }^{3}$ Girijananda Chowdhury Institute of Pharmaceutical Science (GIPS), Azara, Hatkhowapara, NH-37, Guwahati, Assam 781017, ${ }^{4}$ Annai Veilankanni's Pharmacy College, V. G. P. Salai, Saidapet, Chennai 600015, ${ }^{5}$ Koringa College of Pharmacy, Pata, Korangi, Andhra Pradesh 533461

Email: monowar250@gmail.com

Received: 13 Jan 2020, Revised and Accepted: 23 May 2020

\section{ABSTRACT}

Objective: Tuberculosis (TB) is an infectious bacterial disease caused by Mycobacterium tuberculosis which most commonly affects the lungs. TB has the highest mortality rate than any other infectious disease occurs worldwide. The main objective of the present investigation was to develop polymeric nanoparticles based drug delivery system to sustain the ethambutol (ETB) release by reducing the dose frequency.

Methods: The Preformulation studies of drug ETB were done by physical characterization, melting point determination, and UV spectrophotometric analysis. The ETB loaded nanoparticles were prepared by double-emulsion (W/O/W) solvent evaporation/diffusion technique. The prepared polymeric nanoparticles were evaluated for particle size, polydispersity index, zeta potential, drug entrapment efficiency, drug loading, drugpolymer compatibility study, surface morphology, in vitro drug release, and release kinetics.

Results: Based on the result obtained from the prepared formulations, F11 showed the best result and was selected as the optimized formulation Optimized batch (F11) showed better entrapment efficiency (73.3\%), good drug loading capacity (13.21\%), optimum particle size (136.1 nm), and zeta potential $(25.2 \mathrm{mV})$ with $\%$ cumulative drug release of $79.08 \%$ at the end of $24 \mathrm{~h}$.

Conclusion: These results attributed that developed polymeric nanoparticles could be effective in sustaining the ETB release over 24 h. Moreover, the developed nanoparticles could be an alternate method for ETB delivery with a prolonged drug release profile and a better therapeutic effect can be achieved for the treatment of tuberculosis.

Keywords: Mycobacterium tuberculosis, Ethambutol, Eudragit, Polymeric nanoparticle

(C) 2020 The Authors. Published by Innovare Academic Sciences Pvt Ltd. This is an open access article under the CC BY license (http://creativecommons.org/licenses/by/4.0/) DOI: http://dx.doi.org/10.22159/ijap.2020v12i4.36845. Journal homepage: https://innovareacademics.in/journals/index.php/ijap

\section{INTRODUCTION}

Tuberculosis (TB) is a highly contagious persistent infection caused by Mycobacterium tuberculosis and Mycobacterium Bovis and has the highest mortality rate than any other infectious disease. TB is the world's second most common cause of death after HIV/AIDS [1]. Treatment of TB involves the administration of a combination of two or more first-line anti-TB drugs namely, Rifampicin, Isoniazid, and Ethambutol in a fixed proportion in a single dosage form for the initial two months followed by Rifampicin and Isoniazid for four months, described as RHZE2/RH4 [2, 3].

Nanoparticle-based drug delivery systems form the crux of nanomedicine. They are suitable for targeting chronic diseases such as tuberculosis [4]. Experimental data support the possibility of intermittent chemotherapy with key first-line as well as second-line anti-tuberculosis drugs by employing synthetic or natural carriers, chiefly polymers [5]. Besides the sustained release of drugs in plasma and organs, other potential advantages of this system include the possibility of selecting various routes of chemotherapy, reduction in drug dosage, adverse effects, drug interactions, and targeting drug-resistant and latent bacteria [6-8].

Nanoparticles are defined as particulate dispersions or solid particles with a size in the range of $10-1000 \mathrm{~nm}$. The major goals in designing nanoparticles as a delivery system are to control particle size, surface properties [9]. Nanoparticles are prepared majorly by these methods namely solvent evaporation, nanoprecipitation/solvent displacement, ionic gelation or coacervation of hydrophilic polymers, emulsification/solvent diffusion, double emulsification solvent evaporation, supercritical fluid technology, polymerization of monomer dialysis and salting-out method [10-13]. For hydrophilic compounds; encapsulation, double emulsion solvent evaporation is the most popular technique among other methods of preparation. It is hypothesized that by combining the double emulsion evaporation and diffusion technique at the same time could result in a better encapsulation efficiency of hydrophilic molecules in nanoparticles [1416]. The ideal nanoparticles should be biodegradable, stable, nonimmunogenic, non-thrombogenic, non-toxic, easy to fabricate, costeffective, and able to release their payloads only at the target site [17]. The nanoparticles are generally characterized by their size, morphology, and surface charge, using such advanced microscopic techniques as dynamic light scattering (DLS), scanning electron microscopy (SEM), transmission electron microscopy (TEM) and atomic force microscopy (AFM) zeta sizer $[18,19]$.

In the present study, an attempt was made to develop a novel nanoscopic drug delivery portal, polymeric nanoparticles bearing ETB, and evaluated its anti-tuberculosis efficacy by in vitro methods. The prepared nanoparticles were characterized for their size, zeta potential, entrapment efficiency, drug loading, surface morphology, and in vitro drug release profile for monitoring the efficient release of ETB.

\section{MATERIALS AND METHODS}

\section{Materials}

Ethambutol (ETB) was purchased from Sigma Aldrich, St. Louis, MO, USA. Eudragit RS-100 was purchased from Evonik Industries, Essen, Germany. Span 80, PVA, and Methanol were purchased from SD Chemicals, Maharashtra India. Dichloro methane, sodium hydroxide and sodium chloride from Qualigens Fine Chemicals Pvt. Ltd., Mumbai, India. Potassium dihydrogen phosphate and Potassium chloride were purchased from Sisco Research Laboratories Pvt. Ltd., Mumbai, India. All the other reagents and chemicals used were of analytical grade.

\section{Preformulation studies}

Preformulation is a phase of the research and development process to develop stable, safe, and effective dosage forms. In this study, ETB was 
selected as a model anti-tuberculosis drug. The selected drug ETB was identified by various methods like physical characterization, melting point determination, UV-spectrophotometric study, and infrared (IR) spectroscopy [20].

\section{Physical characterization of drug}

ETB was physically characterized based on appearance, color, odor, and taste [20].

\section{Melting point determination}

The capillary melting point apparatus was used to determine the melting point of the drug. The melting point of a drug can be determined by introducing a tiny amount of drug into a one-sided closed small capillary tube. Thermometer attached in a heating bath, the bath was heated slowly and temperatures were observed at which melting begins and is completed [21].

\section{UV spectrophotometric study}

UV spectrophotometric study was carried out to determine the $\lambda$ max of ETB in a phosphate buffer solution of $\mathrm{pH}$ 6.8, hydrochloric acid buffer $\mathrm{pH}$ 1.2, and distilled water as per Indian Pharmacopoeia 2010. A standard stock solution of ETB was prepared by dissolving $100 \mathrm{mg}$ of drug in a $100 \mathrm{ml}$ volumetric flask and the volume was made up to 100 $\mathrm{ml}$ by using phosphate buffer solution of $\mathrm{pH} 6.8$ to get the concentration $1000 \mu \mathrm{g} / \mathrm{ml}$ of standard ETB. From the standard stock solution, $1 \mathrm{ml}$ of sample was pipetted out into a $10 \mathrm{ml}$ volumetric flask and the volume was made up to $10 \mathrm{ml}$ with phosphate buffer solution $\mathrm{pH} 6.8$ to get the concentration $(100 \mu \mathrm{g} / \mathrm{ml})$. Again from this, $1 \mathrm{ml}$ is taken and diluted to $10 \mathrm{ml}$ of phosphate buffer solution 6.8 to get the desired concentration $(10 \mu \mathrm{g} / \mathrm{ml})$ and scanned in the wavelength region between $200 \mathrm{~nm}$ to $400 \mathrm{~nm}$ by using UV-VIS spectrophotometer (Elico UV-SL210, India). The same procedure was repeated with hydrochloric acid buffer pH 1.2 and distilled water [22].

Calibration curve of ETB in phosphate buffer pH
6.8 /hydrochloric acid buffer $\mathrm{pH} 1.2$ /distilled water

A standard stock solution of ETB $(1000 \mu \mathrm{g} / \mathrm{ml})$ was prepared by taking $100 \mathrm{mg}$ of ETB in $100 \mathrm{ml}$ of phosphate buffer $\mathrm{pH}$ 6.8. From the standard stock solution, $1 \mathrm{ml}$ of the sample was further diluted to 10 $\mathrm{ml}$ with phosphate buffer $\mathrm{pH} 6.8$ into a $10 \mathrm{ml}$ volumetric flask and diluted up to the mark. Aliquots of 2, 4, 6, 8, and $10 \mathrm{ml}$ of stock solution were pipetted out into $10 \mathrm{ml}$ volumetric flasks. The volume was made up to the mark with phosphate buffer $\mathrm{pH}$ 6.8. These dilutions give 2,4 , 6,8 , and $10 \mu \mathrm{g} / \mathrm{ml}$ concentration of ETB respectively. The absorbance was measured in the UV-Visible spectrophotometer at $267 \mathrm{~nm}$ using phosphate buffer $\mathrm{pH} 6.8$ as blank and the graph was plotted (concentration versus absorbance). The same procedure was followed for the preparation of the calibration curve of ETB in $0.1 \mathrm{~N} \mathrm{HCl}$ and distilled water respectively [22].

\section{Preparation of ETB loaded polymeric nanoparticles}

The ETB loaded nanoparticles were prepared using a doubleemulsion (W/O/W) solvent evaporation/diffusion technique. Briefly, the specified amount of Eudragit RS-100 was dissolved in 20 $\mathrm{ml}$ of an organic mixture of dichloromethane containing Span 80 $(2 \%, v / v)$ as an emulsifier. $100 \mathrm{mg}$ ETB was dissolved in $5 \mathrm{ml}$ of distilled water and then emulsfied in the polymer solution through magnetic stirring at $1000-1200 \mathrm{rpm}$ for $15 \mathrm{~min}$. The primary W/O emulsion was further added to $25 \mathrm{ml}$ of external water containing poloxamer or PVA as a secondary surfactant with magnetic stirring for $10 \mathrm{~min}$ to achieve the stable double emulsion $(\mathrm{W} / \mathrm{O} / \mathrm{W})$. The nanoparticles suspending in the emulsion were collected by ultracentrifugation at $11000 \mathrm{rpm}$ for $40 \mathrm{~min}$ and washed with distilled water three times. Finally, the products were dried by lyophilization and stored at $-4{ }^{\circ} \mathrm{C}$ for further evaluation [23-26].

\section{Evaluation of ETB loaded polymeric nanoparticles}

\section{Particle size, polydispersity index, and zeta potential}

Particle size, polydispersity index of polymeric nanoparticles was measured by Photon Correlation Spectroscopy using Zetasizer (Beckman Coulter Counter, USA). The zeta potential of the polymeric nanoparticles was measured by the same instruments at $25^{\circ} \mathrm{C}$ [27].

\section{Entrapment efficiency and drug loading}

The entrapment efficiency of ETB was determined by indirect method i.e. by measuring the concentration of the free drug in the aqueous phase of Nano suspension. The amount of free drug was analyzed by a UV-Visible spectrophotometer at a wavelength of 267 $\mathrm{nm}$. The drug entrapment efficiency (EE) and drug loading (DL) was calculated using the following equation [28]:

$$
\begin{gathered}
\text { Entrapment efficiency }(\%)=\frac{\text { Amount of total drug }- \text { Amount of free drug }}{\text { Amount of total drug }} \times 100 \\
\text { Drug loading }(\%)=\frac{\text { Amount of total drug }- \text { Amount of free drug }}{\text { Amount of dry nanoparticles }} \times 100
\end{gathered}
$$

\section{Drug-polymer compatibility study}

The study of the compatibility between the drug and the excipients is an important process in the development of a stable solid dosage form. Incompatibility between drug and excipient can alter the stability and bioavailability of drugs, affecting its safety and efficacy. To determine any type of interaction between the drug and excipients, Fourier-transform infrared (FTIR) spectroscopy and Xray diffraction (XRD) analysis were done for the drug, polymer, physical mixture and formulation [29].

\section{FT-IR spectroscopy}

The FT-IR spectra of ETB, Eudragit RS-100, physical mixture of drug and polymer (1:1), and formulation were observed on the FT-IR spectrophotometer (FTIR-4100, Jasco, Tokyo, Japan) by using $\mathrm{KBr}$ method. The sample was grounded gently with anhydrous $\mathrm{KBr}$ and compressed to form a pellet. The scanning range was 400 and 4000 $\mathrm{cm}^{-1}[30]$.

\section{XRD analysis}

The X-ray diffractograms of ETB, Eudragit RS-100 physical mixture and formulation were procured on an X-ray diffractometer (Rigaku MiniFlex II, Tokyo, Japan) for examining the physical state of ETB and its interaction with other ingredients in the formulation. The source of X-ray was Copper $\mathrm{K} \alpha\left(\lambda=1.5405^{\circ} \mathrm{A}\right)$ monochromatic radiation, operated at $30 \mathrm{kV}$ and $15 \mathrm{~mA}$. The samples were scanned between 2 theta ranges of $10^{\circ}-80^{\circ}[30]$.

\section{Morphological characterization}

The morphological characteristics of prepared nanoparticles were observed by Environmental Scanning Electron Microscope (Quanta 200, FEI Company, Eindhoven, The Netherlands). The samples for SEM were prepared by sprinkling the nanoparticle powder on a double adhesive tape that sticks to an aluminum stub. They were then vacuum-coated with platinum for $45 \mathrm{~s}$. The samples were then randomly scanned and photographs were taken randomly [31].

\section{In vitro drug release studies}

The in vitro drug release of ETB from the polymeric nanoparticles was performed by the dialysis bag diffusion technique. The drug release studies of the ETB solution and ETB loaded Eudragit RS-100 Nanosuspension carried out in $250 \mathrm{ml}$ of phosphate buffer saline $\mathrm{pH} 6.8$ maintained at $37 \pm 2{ }^{\circ} \mathrm{C}$ with a magnetic stirrer with constant heating equipment. A sample of $5 \mathrm{ml}$ of Nano-suspension was filled in a dialysis pouch with the two ends tied by a thread. The $\mathrm{pH}$ value was selected to simulate the physiological $\mathrm{pH}$ of 6.8. Aliquot samples of 5 $\mathrm{ml}$ were withdrawn at the regular interval. The same volume of fresh media was replaced to maintain the sink condition. The aliquots were diluted with fresh media. The amount of drug released was measured by using a UV-Visible spectrophotometer at the wavelength of $267 \mathrm{~nm}$ against phosphate buffer $\mathrm{pH} 6.8$ as a blank [32-34].

\section{Kinetic analysis of drug release data}

To know the mechanism and kinetics of drug release from nanoparticles, in vitro drug release data were fitted to various kinetic models like zero-order model $\left(\mathrm{Q} t=\mathrm{k}_{0} \mathrm{t}\right)$, first-order model $\left(\log Q_{0}-\log Q_{t}=k_{1} t / 2.303\right)$, Higuchi model $\left(Q_{t}=k_{H} \sqrt{t}\right)$ and Korsmeyer-Peppas model $\left(\mathrm{Q}_{\mathrm{t}}=\mathrm{k}_{\mathrm{KP}} \mathrm{t}^{\mathrm{n}}\right)$.

Where $t$ is the time, $Q_{t}$ is the amount of drug released at time $t, Q_{0}$ is the initial amount of the drug in the nanoparticles, $\mathrm{k}_{0}$ is the zero- 
order rate constant, $\mathrm{k}_{1}$ is the first-order rate constant, $\mathrm{k}_{\mathrm{H}}$ is the Higuchi constant reflecting the design variables of the system and $\mathrm{k}_{\mathrm{KP}}$ is the rate constant in Korsmeyer-Peppas model equation and $\mathrm{n}$ is the release exponent $[35,36]$.

\section{Stability studies}

Stability study of the optimized batch of nanoparticles was performed under accelerated stability conditions $\left(40{ }^{\circ} \mathrm{C} \pm 2\right.$ ${ }^{\circ} \mathrm{C} / 75 \pm 5 \% \mathrm{RH}$ ) by keeping in stability testing chamber for three months according to ICH guidelines for stability testing of new products. The samples were withdrawn at a different interval $(0,1$ and $3 \mathrm{mo}$ ) and evaluated in terms of particle size, zeta potential, and entrapment efficiency [37-39].

\section{Data analysis}

The experimental data were processed using Microsoft Excel 2007 software and results were expressed as mean $\pm \mathrm{SD}$.

\section{RESULTS AND DISCUSSION}

\section{Physical characterization of drug}

ETB was evaluated for its physical properties and it was observed that ETB is a white, crystalline powder, almost odorless and bitter in taste with the solubility in chloroform, methylene chloride, and sparingly soluble in water. The physical properties of the ETB were found similar to those reported in Indian Pharmacopoeia 1996 [40].

\section{Melting point determination}

The melting point of ETB was found to be $87.2{ }^{\circ} \mathrm{C}$, which corresponds to the literature value of $87.5{ }^{\circ} \mathrm{C}$ to $88.8{ }^{\circ} \mathrm{C}$ which signifies the identity and purity of the drug [41]

\section{UV spectrophotometric study}

UV Spectrophotometric study was carried out to determine the $\lambda$ max of ETB in phosphate buffer $\mathrm{pH} 6.8$, hydrochloric acid buffer $\mathrm{pH}$ 1.2 , and distilled water. Scanned $\lambda \max$ for ETB was found at $267 \mathrm{~nm}$ in all the Medias [42].

Calibration curve of ETB in phosphate buffer $\mathrm{pH}$ 6.8/hydrochloric acid buffer $\mathrm{pH}$ 1.2/distilled water

The calibration curve of ETB was prepared in phosphate buffer $\mathrm{pH}$ 6.8 , hydrochloric acid buffer $\mathrm{pH} 1.2$, and distilled water. The Rsquare $\left(\mathrm{R}^{2}\right)$ value of the calibration curve in each media was found at almost 0.999 which signifies a statistically linear and straight calibration curve [43]. The $\lambda$ max of the drug was found to be at 267 $\mathrm{nm}$ [44] and no shift in the $\lambda$ max of the drug was observed in different tested Media. The calibration curve of ETB in phosphate buffer $\mathrm{pH}$ 6.8, hydrochloric acid buffer $\mathrm{pH} 1.2$ and distilled water were shown in fig. 1, fig. 2 and fig. 3.

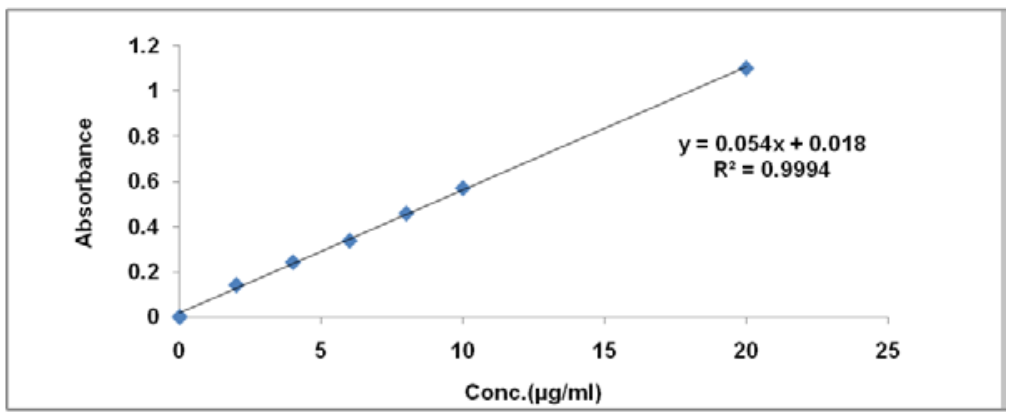

Fig. 1: Calibration curve of ETB in phosphate buffer pH 6.8

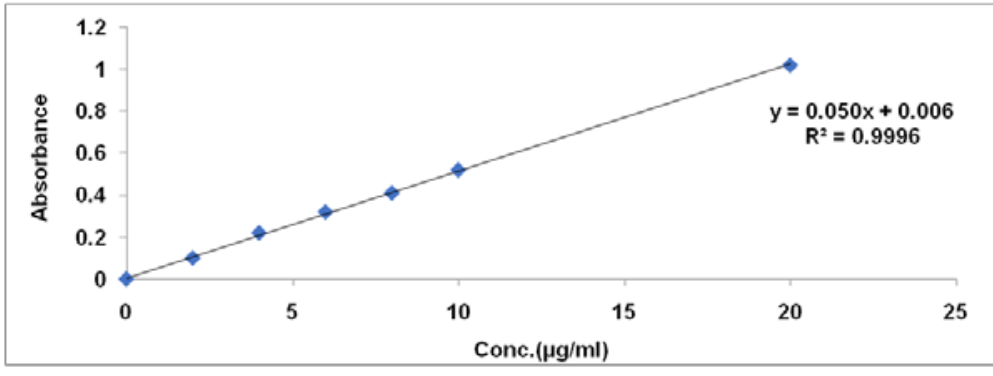

Fig. 2: Calibration curve of ETB in hydrochloric acid buffer pH 1.2

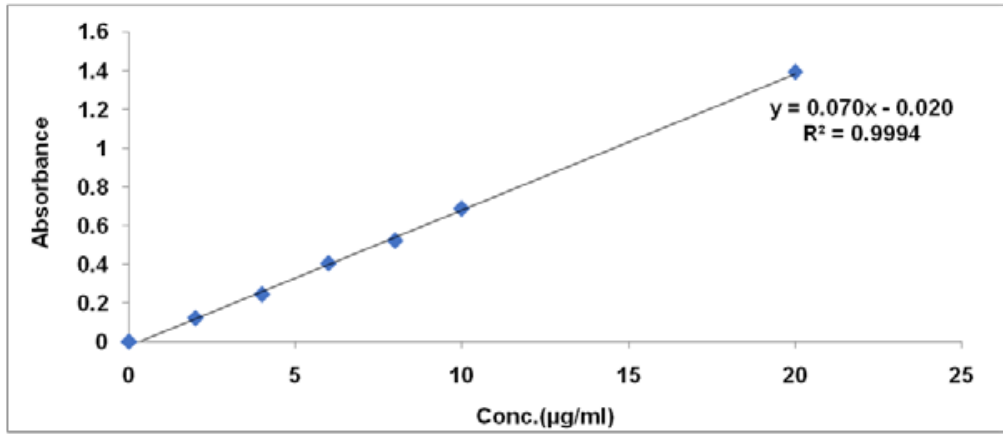

Fig. 3: Calibration curve of ETB in distilled water 


\section{Preparation and evaluation of ETB loaded polymeric nanoparticles}

\section{Effect of various process variables}

The polymeric nanoparticles were prepared by Double-emulsion (W/O/W) solvent evaporation/diffusion technique. The compositions of different formulations were shown in table 1 . The effects of different process variables like different surfactants with varying concentration and steering time on particle size, PDI, zeta potential, $\%$ entrapment efficiency, and \% drug loading were analyzed. The nanoparticles were further optimized in terms of particle size and entrapment efficiency. The in vitro release and stability of polymeric nanoparticles were also studied. The morphological character of ETB loaded polymeric nanoparticles was studied by using scanning electron microscopy.

\section{Effect of stirring time}

The duration of steering has a great impact on the emulsification process and the size of the particle formed [45]. The primary and secondary stirring time was employed during the $\mathrm{W} / \mathrm{O} / \mathrm{W}$ emulsification process. At low stirring time 10:5 min (Primary stirring time: secondary stirring time); $15: 5$ min (primary stirring time: secondary stirring time) the emulsion was not formed properly. But at high stirring time 20:10 min (primary stirring time: secondary stirring time) the emulsification was found to be optimum for the formation of stable $\mathrm{W} / \mathrm{O} / \mathrm{W}$ emulsion.

\section{Effect of secondary surfactant}

The influence of different types of surfactants was also investigated The type and concentration of surfactant also impact on the stability of emulsion and size of particles as well $[46,47]$. The average particle size, polydispersity index (PDI) of the ETB loaded Eudragit RS-100 nanoparticles are illustrated in table 2. The particle size and PDI were signficantly affected by the surfactant. A small particle size $(45.5 \mathrm{~nm})$ with low PDI (0.237) was obtained when the poloxamer solution was used as an aqueous surfactant compared to the PVA batch where the particle size and PDI were $81.80 \mathrm{~nm}$ and 0.248 respectively. Thesefindings suggest that poloxamer 188 is more efficient in stabilizing the emulsion with smaller particles as compared to PVA.

Table 1: Composition of different formulations

\begin{tabular}{lllll}
\hline Batch & Drug & Polymer & Surfactant & Ratio \\
\hline F1 & ETB & EUDRAGIT RS-100 & PVA(45000) & $1: 0.5$ \\
F2 & ETB & EUDRAGIT RS-100 & PVA(45000) & $1: 1$ \\
F3 & ETB & EUDRAGIT RS-100 & PVA(45000) & $1: 2$ \\
F4 & ETB & EUDRAGIT RS-100 & PVA(125000) & $1: 3$ \\
F5 & ETB & EUDRAGIT RS-100 & PVA(125000) & $1: 1$ \\
F6 & ETB & EUDRAGIT RS-100 & PVA(125000) & $1: 2$ \\
F7 & ETB & EUDRAGIT RS-100 & POLOXAMER 188 & $1: 3$ \\
F8 & ETB & EUDRAGIT RS-100 & POLOXAMER 188 & $1: 0.5$ \\
F9 & ETB & EUDRAGIT RS-100 & POLOXAMER 188 188 & $1: 1$ \\
F10 & ETB & EUDRAGIT RS-100 & POLOXAMER 407 & $1: 2$ \\
F11 & ETB & EUDRAGIT RS-100 & POLOXAMER 407 & $1: 0.5$ \\
F12 & ETB & EUDRAGIT RS-100 & POLOXAMER 407 407 & $1: 2$ \\
F13 & ETB & EUDRAGIT RS-100 & $1: 3$ \\
F14 & ETB & EUDRAGIT RS-100 & \\
F15 & ETB & EUDRAGIT RS-100 & & \\
F16 & ETB & EUDRAGIT RS-100 & & \\
\hline
\end{tabular}

\section{Particle size}

The particle size of prepared nanoparticles was observed in the range of $45.51 \mathrm{~nm}$ to $300.4 \mathrm{~nm}$. The amount of polymer used in the formulation has a great impact on the size of the particles formed [48]. In this study also the amount of EUDRAGIT RS-100 has shown a significant effect on particle size. Increasing EUDRAGIT RS-100 concentration led to an increase in viscosity of the organic phase, hence reducing the net shear stress and promoting the formation of a droplet with the larger size. Also, an increase in the surfactant concentration i.e. PVA or poloxamer significantly decreases the particle size. Nanoparticles smaller than $10 \mathrm{~nm}$ can be rapidly cleared by the kidneys or through extravasation, while larger nanoparticles may have a higher tendency to be cleared by cells of the mononuclear phagocyte system [49]. It was observed that nanoparticles $<100 \mathrm{~nm}$ have a higher potential to circulate in the blood for long periods and experience reduced hepatic filtration [50].

Table 2: Particle size, polydispersity index, and zeta potential of prepared formulation

\begin{tabular}{llll}
\hline Batch & Particle size (nm) & PDI & Zeta potential (mV) \\
\hline F1 & 136.0 & 0.299 & 3.23 \\
F2 & 277.8 & 0.248 & 5.03 \\
F3 & 81.8 & 0.448 & 3.53 \\
F4 & 117.8 & 0.325 & 11.10 \\
F5 & 248.4 & 0.823 & 6.24 \\
F6 & 131.6 & 0.369 & 13.24 \\
F7 & 300.4 & 0.286 & 9.24 \\
F8 & 247.5 & 0.274 & 8.98 \\
F9 & 106.0 & 0.672 & 3.64 \\
F10 & 247.5 & 0.274 & 13.70 \\
F11 & 136.0 & 0.299 & 25.20 \\
F12 & 133.2 & 0.481 & 13.20 \\
F13 & 139.3 & 0.287 & 4.23 \\
F14 & 87.6 & 0.314 & 1.16 \\
F15 & 66.1 & 0.237 & \\
F16 & 45.5 & 0.364 & \\
\end{tabular}




\section{The polydispersity index (PDI)}

PDI of nanoparticles was observed in the range of 0.237 to 0.672 with a low coefficient of variation value of 0.11 . Generally, PDI ranges from Zero to One. Results suggest that a high surfactant concentration $(1 \%, \mathrm{w} / \mathrm{v}$ or higher) leads to smaller particles with a satisfactory PDI and this may be attributed to the fact that higher surfactant concentration ensures a good emulsification process and therefore leads to the formation of particles of small size and with uniform size distribution [51].

\section{Zeta potential}

Zeta potential of the optimized batch was found to be $+25.2 \mathrm{mV}$ (Nanoparticles with a zeta potential between- 10 and $+10 \mathrm{mV}$ are considered relatively neutral, while nanoparticles with zeta potentials of greater than $+25 \mathrm{mV}$ or less than- $25 \mathrm{mV}$ are considered strongly cationic and strongly anionic, respectively and stable [52]. The positive charge of nanoparticles is due to the carboxyl group of EUDRAGIT RS-100.

\section{Entrapment efficiency (EE)}

The $\%$ entrapment efficiency was found to be high for the hydrophilic nature of drugs lying between 61.4 to $80.9 \%$ and results were shown in table 3. The difference in entrapment efficiency mainly depends upon the amount of Eudragit RS-100 and the concentration of surfactant [53]. The amount of Eudragit RS-100 shows a significant effect on entrapment efficiency, since increasing Eudragit RS-100 concentration led to an increase in viscosity of the organic phase. Increasing viscosity could increase the drug resistance diffusion into the aqueous phase and thus enhance the drug entrapment efficiency. With the increase of poloxamer concentration, particle size decreases which leads to low entrapment of drugs.

\section{Drug loading (DL)}

The $\%$ drug loading was found to be in the range of $13.21 \%$ to $42.7 \%$ and results were shown in table 3. The amount of Eudragit RS-100 showed a significant effect on \% DL. With the increase of EUDRAGIT RS-100 concentration the \% DL decreased.

Table 3: Entrapment efficiency (\% EE), drug loading (\% DL) and cumulative drug release (\% CDR) of prepared batches of formulation

\begin{tabular}{llll}
\hline Batch & \% EE & \% DL & \% CDR \\
\hline F1 & $76.98 \pm 0.06$ & $42.54 \pm 0.02$ & $82.25 \pm 0.31$ \\
F2 & $74.10 \pm 0.03$ & $25.12 \pm 0.01$ & $80.26 \pm 0.24$ \\
F3 & $69.50 \pm 0.21$ & $17.12 \pm 0.02$ & $79.82 \pm 0.56$ \\
F4 & $65.12 \pm 0.30$ & $10.23 \pm 0.02$ & $73.25 \pm 0.25$ \\
F5 & $66.27 \pm 0.16$ & $38.70 \pm 0.12$ & $79.82 \pm .024$ \\
F6 & $67.12 \pm .01$ & $26.73 \pm 0.32$ & $79.59 \pm 0.29$ \\
F7 & $72.24 \pm 0.02$ & $20.12 \pm 0.21$ & $76.23 \pm 0.65$ \\
F8 & $75.04 \pm 0.045$ & $13.23 \pm 0.34$ & $77.11 \pm 0.75$ \\
F9 & $61.40 \pm 0.02$ & $39.97 \pm 0.25$ & $73.90 \pm 0.65$ \\
F10 & $63.20 \pm 0.012$ & $27.37 \pm 0.31$ & $\mathbf{7 9 . 0 8} \pm \mathbf{0 . 4 2}$ \\
F11 & $\mathbf{7 3 . 3 0 \pm 0 . 1 4}$ & $\mathbf{1 3 . 2 1} \pm \mathbf{0 . 6 5}$ & $78.23 \pm 0.02$ \\
F12 & $75.20 \pm 0.24$ & $10.24 \pm 0.02$ & $80.73 \pm 0.04$ \\
F13 & $69.22 \pm 0.03$ & $40.20 \pm 0.21$ & $80.79 \pm 0.216$ \\
F14 & $66.01 \pm 0.01$ & $27.96 \pm 0.31$ & $76.88 \pm 0.24$ \\
F15 & $72.25 \pm 0.014$ & $19.60 \pm 0.21$ & $\mathbf{7 5 . 9 0 \pm 0 . 0 3 6}$ \\
F16 & $\mathbf{7 5 . 2 3 \pm 0 . 0 2}$ & $15.20 \pm 0.24$ & \\
\hline
\end{tabular}

Results are presented as mean $\pm \mathrm{SD}(\mathrm{n}=3)$.

\section{FT-IR spectroscopy}

The FT-IR spectra of Eudragit RS-100 appeared at $1727.21 \mathrm{~cm}^{-1}$ for the carbonyl peak ( $\mathrm{C}=0$ stretching) which corresponds to the FTIR spectra of Eudragit RS-100 found in the literature [54]. FT-IR spectra of ETB show the broad peak at $3414-3200 \mathrm{~cm}^{-1}\left(\mathrm{NH}_{2}\right.$ stretching), at 3000 $2850 \mathrm{~cm}^{-1}$ (-CH stretching) and at $1713.72 \mathrm{~cm}^{-1}$ for the carbonyl peak ( $\mathrm{C}=0$ stretching) which were similar with the standard ETB [55]. In the formulation of Eudragit RS-100 and ETB, all the characteristic peaks of polymer and the drug are retained showing no significant interaction between them. The FT-IR spectra of ETB, Eudragit RS-100, and optimized formulations were shown in fig. 4, fig. 5 and fig. 6.

\section{XRD analysis}

The diffraction pattern of pure ETB shows that the drug is crystalline in nature, with many characteristic peaks observed between 11-45 ( $2 \theta$ value). The XRD pattern of the ETB loaded polymeric nanoparticles shows that most of the characteristic peaks of ETB were retained which suggests that no significant incompatibility between drug and other excipients within polymeric nanoparticles. The XRD of ETB shows sharp picks which implies the crystalline nature of the formulation [56]. The XRD spectra of ETB, Eudragit RS-100, ETB-Eudragit RS-100 physical mixture, and optimized formulation were shown in fig. 7 .

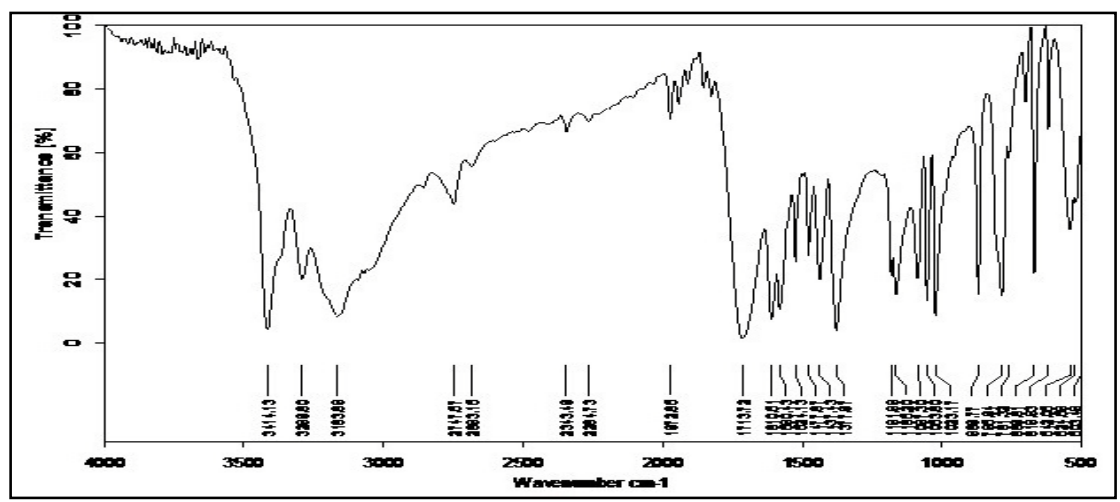

Fig. 4: FTIR spectra of ethambutol 


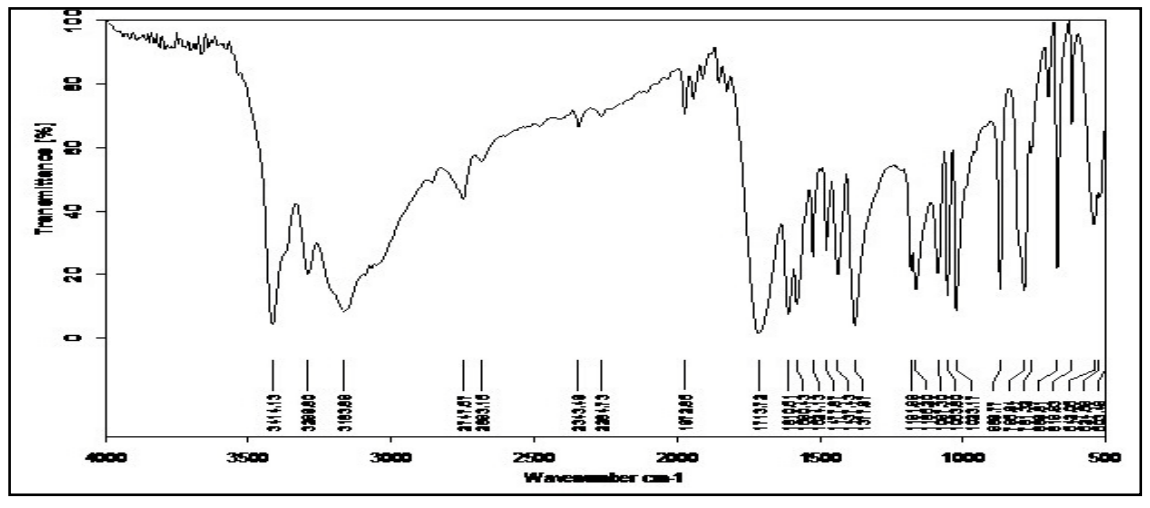

Fig. 5: FTIR spectra of eudragit RS-100

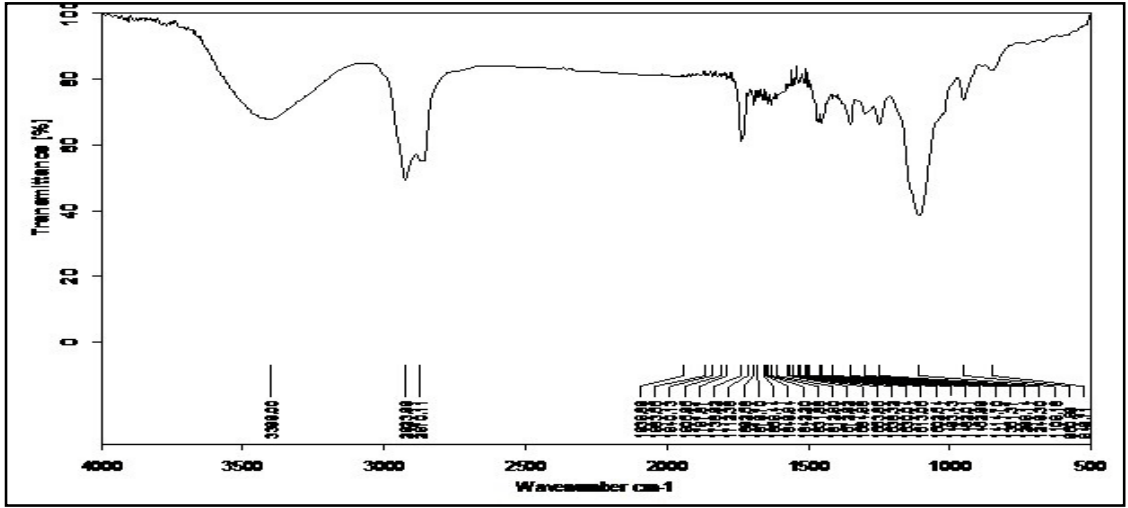

Fig. 6: FTIR spectra of optimized formulations

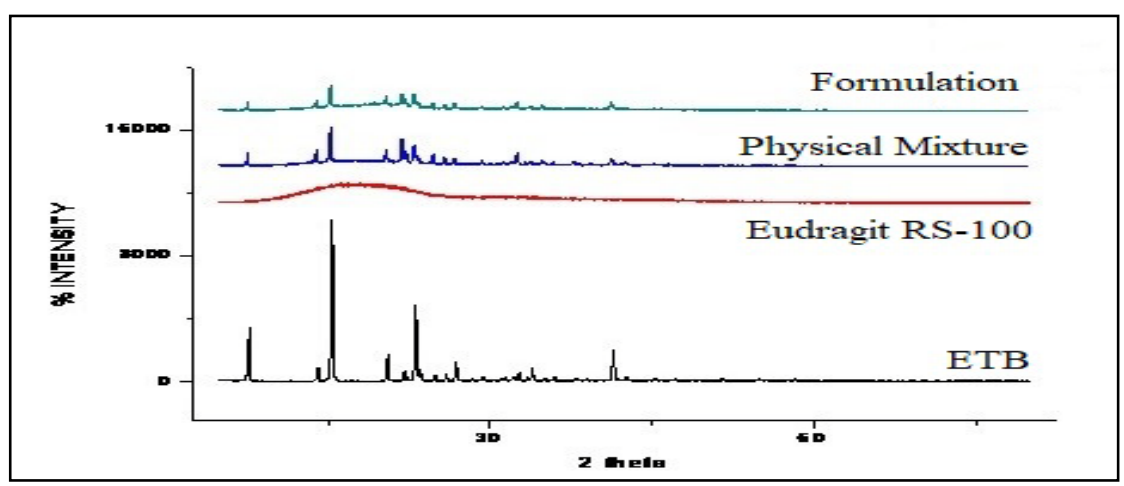

Fig. 7: X-ray diffractograms of ETB, Eudragit RS-100, physical mixture, and optimized formulation

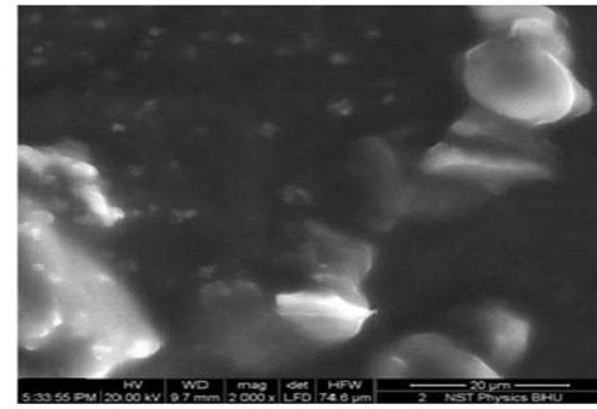

A

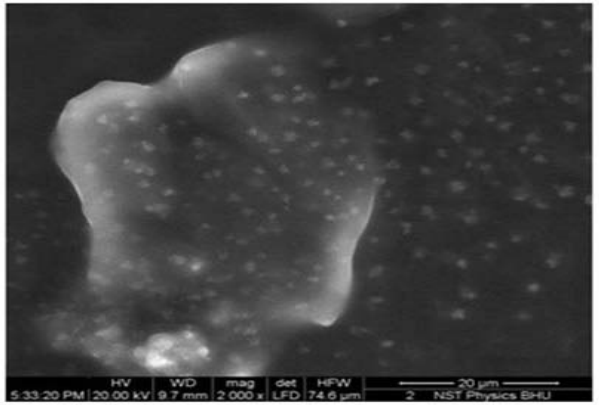

B

Fig. 8: SEM photographs 


\section{Morphological characterization}

The external morphology of the nanoparticles was studied using SEM revealed that all nanoparticles are somewhat spherical in shape and are of Nano-size range but with substantial agglomeration. The degree of nanoparticle fusion was notable in fig. 8 (A and B). A reason for this behavior was that during the lyophilization process solvent was removed from nanoformulation. This affected the droplet equilibrium resulting in coalescence and agglomeration during the early step of lyophilization [57]. The surface of nanoparticles was smooth with few very small pores which seem to be associated with evaporation of solvent from the surface.

\section{In vitro drug release studies}

The in vitro release study was performed in phosphate buffer $\mathrm{pH} 6.8$ and the study was continued up to $24 \mathrm{~h}$. The results of in vitro dissolution studies on the polymeric nanoparticles, F1 to F16 were shown in table 4 to table 7 . The results allow for the following observations and inferences.

When ETB pure drug was studied for its dissolution, it was seen that a high percent (\%) of ETB was dissolved within $1 \mathrm{~h}$. Almost all the drug $(90 \%)$ dissolved within $6 \mathrm{~h}$ and later there was no further release.
Formulations F1 to F16: Formulations F1 to F4 prepared using PVA (45000) sustained the drug release as the time prolonged. These formulations showed a biphasic release profile; an initial sustained release phase up to $11 \mathrm{~h}$ followed by a controlled release phase up to 24 $\mathrm{h}$. The initial burst release of the drug is due to the presence of the drug on the surface of particles. The sustained release pattern of the drug may be attributed to the alteration in the stability and swelling profile of the polymeric matrix system. The release was gradual and controlled; and by the end of $24 \mathrm{~h}, 82 \%$ of the drug was released from formulation F1.

Formulations F5 to F8 prepared using PVA (125000) sustained the drug release as the time prolonged. These formulations showed a biphasic release profile. The release was gradual and controlled and by the end of $24 \mathrm{~h}, 82 \%$ of the drug was released from formulation F5. In this study the $\%$ drug release from the NPs was found around $80 \%$ when PVA was used as a stabilizer which is similar to the study carried out by Dustin et al. [58].

Formulations F13 to F16 prepared using poloxamer 407 sustained the drug release as the time prolonged. These formulations showed a biphasic release profile. This type of sustained-release pattern of the drug is more pronounced in the presence of poloxamer as a stabilizing agent, due to the alteration in the stability of the polymeric matrix system. The release was gradual and controlled and by the end of $24 \mathrm{~h}$ $81 \%$ of the drug was released from formulation F14.

Table 4: In vitro drug release studies of ETB and prepared formulations using PVA (45000 da)

\begin{tabular}{|c|c|c|c|c|c|}
\hline Time (h) & ETB Aq. Sol & F1 & F2 & F3 & F4 \\
\hline 0 & 0 & 0 & 0 & 0 & 0 \\
\hline 0.25 & $12.25 \pm 0.02$ & $6.37 \pm 0.23$ & $8.57 \pm 0.31$ & $6.37 \pm 0.36$ & $6.37 \pm 0.36$ \\
\hline 0.5 & $18.98 \pm 0.02$ & $11.26 \pm 0.23$ & $11.26 \pm 0.03$ & $11.26 \pm 0.45$ & $11.26 \pm 0.45$ \\
\hline 0.75 & $26.69 \pm 0.10$ & $12.98 \pm 0.24$ & $12.98 \pm 0.04$ & $12.98 \pm 0.56$ & $12.98 \pm 0.56$ \\
\hline 1 & $29.95 \pm 0.23$ & $21.06 \pm 0.02$ & $18.36 \pm 0.03$ & $21.06 \pm 0.36$ & $21.06 \pm 0.36$ \\
\hline 1.5 & $35.60 \pm 0.12$ & $24.24 \pm 0.0 .21$ & $21.79 \pm 0.05$ & $24.24 \pm 0.46$ & $24.24 \pm 0.46$ \\
\hline 2 & $46.20 \pm 0.13$ & $29.38 \pm 0.24$ & $29.38 \pm 0.04$ & $29.38 \pm 0.25$ & $29.38 \pm 0.25$ \\
\hline 3 & $53.20 \pm 0.13$ & $32.25 \pm 0.014$ & $30.25 \pm 0.26$ & $33.25 \pm 0.45$ & $33.25 \pm 0.45$ \\
\hline 4 & $68.97 \pm 0.21$ & $35.26 \pm 0.14$ & $37.46 \pm 0.36$ & $35.26 \pm 0.62$ & $35.26 \pm 0.62$ \\
\hline 5 & $86.24 \pm 0.56$ & $42.85 \pm 0.14$ & $45.54 \pm 0.46$ & $42.85 \pm 0.45$ & $42.85 \pm 0.45$ \\
\hline 6 & $96.24 \pm 0.47$ & $47.25 \pm 0.23$ & $47.25 \pm 0.64$ & $45.53 \pm 0.15$ & $47.25 \pm 0.23$ \\
\hline 7 & $98.25 \pm 0.55$ & $51.41 \pm 0.21$ & $48.97 \pm 0.23$ & $46.53 \pm 0.01$ & $48.97 \pm 0.12$ \\
\hline 8 & & $54.60 \pm 0.24$ & $54.60 \pm 0.54$ & $51.00 \pm 0.23$ & $54.60 \pm 0.02$ \\
\hline 9 & & $58.51 \pm 0.14$ & $59.98 \pm 0.35$ & $56.00 \pm 0.14$ & $59.98 \pm 0.04$ \\
\hline 10 & & $67.33 \pm 0.56$ & $64.88 \pm 0.36$ & $63.00 \pm 0.23$ & $64.88 \pm 0.03$ \\
\hline 11 & & $70.76 \pm 0.65$ & $78.35 \pm 0.45$ & $72.23 \pm 0.01$ & $68.25 \pm 0.32$ \\
\hline 12 & & $75.41 \pm 0.32$ & $79.25 \pm 0.46$ & $76.20 \pm 0.02$ & $69.26 \pm 0.04$ \\
\hline 24 & & $82.25 \pm 0.75$ & $80.26 \pm 0.36$ & $79.82 \pm 0.13$ & $73.25 \pm 0.02$ \\
\hline
\end{tabular}

Results are presented as mean \pm SD $(n=3)$.

Table 5: In vitro drug release profile of prepared formulations using PVA (125000 da)

\begin{tabular}{|c|c|c|c|c|}
\hline Time (h) & F5 & F6 & F7 & F8 \\
\hline 0 & 0 & 0 & 0 & 0 \\
\hline 0.25 & $8.57 \pm 0.03$ & $6.37 \pm 0.26$ & $5.39 \pm 0.31$ & $4.65 \pm 0.31$ \\
\hline 0.5 & $11.26 \pm 0.01$ & $11.26 \pm 0.23$ & $6.37 \pm 0.12$ & $6.37 \pm 0.01$ \\
\hline 0.75 & $12.98 \pm 0.32$ & $12.98 \pm 0.36$ & $11.26 \pm 0.21$ & $9.55 \pm 0.02$ \\
\hline 1 & $18.36 \pm 0.36$ & $21.06 \pm 0.24$ & $12.98 \pm 0.14$ & $12.98 \pm 0.31$ \\
\hline 1.5 & $21.79 \pm 0.25$ & $24.24 \pm 0.26$ & $21.06 \pm 0.25$ & $21.06 \pm 0.21$ \\
\hline 2 & $25.00 \pm 0.24$ & $29.38 \pm 0.56$ & $24.24 \pm 0.12$ & $24.24 \pm 0.42$ \\
\hline 3 & $34.03 \pm 0.36$ & $32.20 \pm 0.24$ & $33.45 \pm 0.01$ & $36.45 \pm 0.24$ \\
\hline 4 & $37.46 \pm 0.45$ & $35.26 \pm 0.36$ & $35.26 \pm 0.02$ & $38.93 \pm 0.36$ \\
\hline 5 & $45.54 \pm 0.36$ & $42.85 \pm 0.45$ & $42.85 \pm 0.35$ & $42.85 \pm 0.24$ \\
\hline 6 & $47.25 \pm 0.45$ & $47.25 \pm 0.78$ & $47.25 \pm 0.21$ & $47.25 \pm 0.25$ \\
\hline 7 & $48.97 \pm 0.23$ & $51.41 \pm 0.62$ & $51.41 \pm 0.25$ & $51.41 \pm 0.26$ \\
\hline 8 & $54.60 \pm 0.01$ & $54.60 \pm 0.35$ & $54.60 \pm 0.21$ & $54.60 \pm 0.24$ \\
\hline 9 & $59.98 \pm 0.25$ & $58.51 \pm 0.21$ & $58.51 \pm 0.45$ & $58.51 \pm 0.36$ \\
\hline 10 & $64.88 \pm 0.15$ & $67.33 \pm 0.36$ & $67.33 \pm 0.42$ & $67.33 \pm 0.25$ \\
\hline 11 & $78.35 \pm 0.25$ & $70.76 \pm 0.14$ & $74.48 \pm 0.25$ & $70.76 \pm 0.26$ \\
\hline 12 & $81.28 \pm 0.36$ & $75.41 \pm 0.02$ & $75.08 \pm 0.21$ & $75.90 \pm 0.36$ \\
\hline 24 & $81.82 \pm 0.25$ & $79.82 \pm 0.21$ & $75.59 \pm 0.12$ & $79.57 \pm 0.45$ \\
\hline
\end{tabular}

Results are presented as mean $\pm \mathrm{SD}(\mathrm{n}=3)$. 
Table 6: In vitro drug release studies prepared formulations using poloxamer 188

\begin{tabular}{|c|c|c|c|c|}
\hline Time (h) & F9 & F10 & F11 & F12 \\
\hline 0 & 0 & 0 & 0 & 0 \\
\hline 0.25 & $1.38 \pm 0.21$ & $8.32 \pm 0.24$ & $7.34 \pm 0.02$ & $5.63 \pm 0.21$ \\
\hline 0.5 & $2.75 \pm 0.31$ & $15.91 \pm 0.32$ & $11.75 \pm 0.01$ & $8.57 \pm 0.23$ \\
\hline 0.75 & $4.13 \pm 0.45$ & $19.10 \pm 0.25$ & $16.89 \pm 0.01$ & $14.45 \pm 0.24$ \\
\hline 1 & $5.50 \pm 0.02$ & $23.26 \pm 0.24$ & $21.79 \pm 0.04$ & $21.79 \pm 0.23$ \\
\hline 1.5 & $8.25 \pm 0.01$ & $29.38 \pm 0.23$ & $27.91 \pm 0.05$ & $27.42 \pm 0.25$ \\
\hline 2 & $11.00 \pm 0.03$ & $35.50 \pm 0.65$ & $30.85 \pm 0.05$ & $33.30 \pm 0.25$ \\
\hline 3 & $16.50 \pm 0.05$ & $41.22 \pm 0.25$ & $35.50 \pm 0.32$ & $35.75 \pm 0.26$ \\
\hline 4 & $22.00 \pm 0.32$ & $45.54 \pm 0.25$ & $41.13 \pm 0.01$ & $40.40 \pm 0.02$ \\
\hline 5 & $27.50 \pm 0.01$ & $48.72 \pm 0.12$ & $45.54 \pm 0.05$ & $43.58 \pm 0.03$ \\
\hline 6 & $33.00 \pm 0.03$ & $51.90 \pm 0.21$ & $48.72 \pm 0.02$ & $47.99 \pm 0.01$ \\
\hline 7 & $38.50 \pm 0.05$ & $57.78 \pm 0.31$ & $51.90 \pm 0.06$ & $53.86 \pm 0.04$ \\
\hline 8 & $44.00 \pm 0.32$ & $59.98 \pm 0.01$ & $55.33 \pm 0.14$ & $56.31 \pm 0.05$ \\
\hline 9 & $49.50 \pm 0.42$ & $61.94 \pm 0.02$ & $71.40 \pm 0.25$ & $63.41 \pm 0.06$ \\
\hline 10 & $55.01 \pm 0.12$ & $68.06 \pm 0.02$ & $70.35 \pm 0.36$ & $64.64 \pm 0.05$ \\
\hline 11 & $60.51 \pm 0.32$ & $73.20 \pm 0.03$ & $70.35 \pm 0.45$ & $71.98 \pm 0.12$ \\
\hline 12 & $66.01 \pm 0.10$ & $75.90 \pm 0.04$ & $69.58 \pm 0.36$ & $76.39 \pm 0.04$ \\
\hline 24 & $76.23 \pm 0.32$ & $77.12 \pm 0.02$ & $73.93 \pm 0.12$ & $79.08 \pm 0.05$ \\
\hline
\end{tabular}

Results are presented as mean \pm SD $(n=3)$.

Table 7: In vitro drug release studies prepared formulations using poloxamer 407

\begin{tabular}{lllll}
\hline Time (h) & F13 & F14 & F15 \\
\hline 0 & 0 & 0 & 0 & $7.34 \pm 0.24$ \\
0.25 & $1.38 \pm 0.02$ & $9.55 \pm 0.05$ & $13.71 \pm 0.23$ \\
0.5 & $2.75 \pm 0.03$ & $13.71 \pm 0.03$ & $19.10 \pm 0.15$ & $8.32 \pm 0.02$ \\
0.75 & $4.13 \pm 0.04$ & $16.89 \pm 0.02$ & $24.24 \pm 0.26$ & $11.75 \pm 0.04$ \\
1 & $5.50 \pm 0.25$ & $23.50 \pm 0.05$ & $29.38 \pm 0.13$ & $13.71 \pm 0.05$ \\
1.5 & $8.25 \pm 0.15$ & $25.22 \pm 0.03$ & $33.30 \pm 0.15$ & $24.24 \pm 0.25$ \\
2 & $11.00 \pm 0.45$ & $30.85 \pm 0.05$ & $38.19 \pm 0.14$ & $30.36 \pm 0.15$ \\
3 & $16.50 \pm 0.04$ & $36.23 \pm 0.04$ & $45.54 \pm 0.13$ \\
4 & $22.00 \pm 0.03$ & $45.54 \pm 0.06$ & $48.72 \pm 0.17$ \\
5 & $27.50 \pm 0.35$ & $48.23 \pm 0.05$ & $51.41 \pm 0.10$ \\
6 & $33.00 \pm 0.42$ & $51.41 \pm 0.36$ & $55.33 \pm 0.05$ & $32.02 \pm 0.24$ \\
7 & $38.50 \pm 0.24$ & $57.78 \pm 0.24$ & $57.54 \pm 0.09$ \\
8 & $44.00 \pm 0.23$ & $59.98 \pm 0.26$ & $64.88 \pm 0.08$ \\
9 & $49.50 \pm 0.15$ & $62.92 \pm 0.24$ & $70.76 \pm 0.08$ \\
10 & $55.01 \pm 0.01$ & $65.37 \pm 0.15$ & $71.98 \pm 0.01$ \\
11 & $60.51 \pm 0.02$ & $70.76 \pm 0.12$ & $73.45 \pm 0.05$ \\
24 & $66.01 \pm 0.03$ & $78.35 \pm 0.15$ & $76.88 \pm 0.15$ \\
\hline
\end{tabular}

Results are presented as mean $\pm \operatorname{SD}(n=3)$.

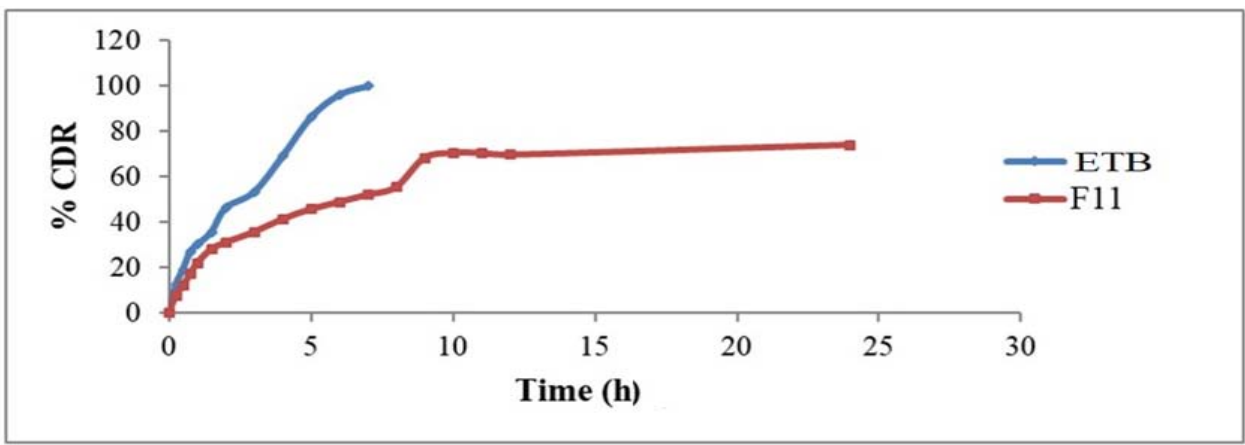

Fig. 9: In vitro drug release profile of pure drug ETB and formulation F11 in Phosphate buffer pH 6.8

\section{Kinetic analysis of drug release data}

The drug release mechanism and kinetics from the NPs were investigated by fitting the drug release data in various kinetic models. After the model fitting the correlational coefficient $\left(R^{2}\right)$ of the various kinetic models (table 8) was compared and it has been seen that the Korsmeyer-Peppas (K-P) model was found to be best fitted for optimized formulation F11. The $n$ value $(0.43)$ indicates the release pattern of the drug from NPs was maintained by the Fickian diffusion mechanism [59]. 
Table 8: Correlational coefficient $\left(R^{2}\right)$ of the various kinetic models

\begin{tabular}{|c|c|c|c|c|c|c|c|}
\hline \multirow[t]{2}{*}{ Batch } & \multicolumn{2}{|c|}{ Zero order model } & \multicolumn{2}{|c|}{ First order model } & \multirow{2}{*}{$\begin{array}{l}\text { Higuchi model } \\
\mathbf{R}^{2}\end{array}$} & \multicolumn{2}{|c|}{ K-P model } \\
\hline & $\mathbf{K}_{\mathbf{0}}$ & $\mathbf{R}^{2}$ & $\mathbf{K}_{1}$ & $\mathbf{R}^{2}$ & & $\mathbf{R}^{2}$ & $\mathbf{n}$ \\
\hline F1 & 3.45 & 0.895 & 0.086 & 0.798 & 0.958 & 0.967 & 0.478 \\
\hline $\mathrm{F} 2$ & 3.54 & 0.937 & 0.073 & 0.782 & 0.939 & 0.956 & 0.523 \\
\hline F3 & 3.25 & 0.824 & 0.071 & 0.783 & 0.937 & 0.949 & 0.489 \\
\hline $\mathrm{F} 4$ & 3.28 & 0.826 & 0.073 & 0.782 & 0.937 & 0.95 & 0.487 \\
\hline F5 & 3.25 & 0.826 & 0.075 & 0.786 & 0.94 & 0.959 & 0.535 \\
\hline F6 & 3.45 & 0.895 & 0.081 & 0.795 & 0.958 & 0.967 & 0.478 \\
\hline F7 & 3.36 & 0.876 & 0.075 & 0.786 & 0.765 & 0.722 & 0.562 \\
\hline F8 & 3.65 & 0.889 & 0.073 & 0.793 & 0.954 & 0.961 & 0.596 \\
\hline F9 & 3.54 & 0.92 & 0.072 & 0.881 & 0.967 & 0.968 & 0.51 \\
\hline F10 & 3.38 & 0.832 & 0.066 & 0.725 & 0.938 & 0.964 & 0.408 \\
\hline F11 & 3.4 & 0.79 & 0.065 & 0.728 & 0.939 & 0.947 & 0.435 \\
\hline F12 & 3.61 & 0.872 & 0.073 & 0.766 & 0.949 & 0.967 & 0.439 \\
\hline F13 & 3.33 & 0.876 & 0.083 & 0.752 & 0.948 & 0.964 & 0.45 \\
\hline F14 & 3.56 & 0.963 & 0.076 & 0.761 & 0.954 & 0.968 & 0.439 \\
\hline F15 & 3.25 & 0.835 & 0.068 & 0.729 & 0.938 & 0.967 & 0.347 \\
\hline F16 & 3.45 & 0.871 & 0.073 & 0.788 & 0.954 & 0.954 & 0.495 \\
\hline
\end{tabular}

\section{Selection and optimization of prototype formula}

The optimization was aimed at maximizing \% entrapment efficiency and \% drug loading of ETB in the formulation while minimizing particle size for the new formulation. Sixteen formulations were prepared and optimized by changing the drug: polymer ratio, type of surfactant. Particle size and drug entrapment efficiency were in the range of $45.51 \mathrm{~nm}$ to $300.4 \mathrm{~nm}$ and $61.4 \%$ to $80.9 \%$ respectively. Polydispersity index was in the range of 0.237 to 0.672 with a low coefficient of variation value of 0.11 . Among the entire batches prepared, the F11 batch was considered as optimized formulation showing the best results in terms of desired particle size, PDI, Zeta Potential, and good entrapment efficiency and \% drug loading. Based on the result of these six batches, optimized batch (F11) was prepared using EUDRAGIT RS-100, poloxamer188 (1\% w/v) and the optimized has shown better entrapment efficiency $(73.3 \%)$, drug loading (13.21\%) and optimum particle size (136 nm).

\section{Stability studies}

The stability of optimized, ETB loaded polymeric nanoparticles developed in the present study was evaluated as per International Conference on Harmonization (ICH) guidelines. The storage conditions recommended by ICH for stability testing are summarized in table 9 and table 10.

The storage conditions for accelerated testing are $40{ }^{\circ} \mathrm{C} \pm 2{ }^{\circ} \mathrm{C}$, $75 \pm 5 \% \mathrm{RH}$ for $6 \mathrm{mo}$ as per ICH and WHO guidelines. If the product is unstable in the above conditions, intermediate conditions $\left(30^{\circ} \mathrm{C} \pm 2\right.$ ${ }^{\circ} \mathrm{C}, 65 \pm 5 \% \mathrm{RH}$ ) are recommended. WHO has prescribed testing at 0 , $1,2,3$, and 6 mo during storage. ICH has not given testing timefrequency [60]. In the present study, as the formulations developed comes under the category of solid oral dosage forms/solids for reconstitution/dry and lyophilized powders in vials, a storage condition of $40 \pm 2{ }^{\circ} \mathrm{C}, 75 \pm 5 \% \mathrm{RH}$ for 6 mo was used as per accelerated stability studies.

Table 9: Effect of storage condition $\left(40 \pm 2{ }^{\circ} \mathrm{C} / 75 \pm 5 \% \mathrm{RH}\right)$ on characterization parameters of optimized formulation (F11)

\begin{tabular}{llll}
\hline Parameters & 0 D & 30 D & 60 D \\
\hline Particle Size $(\mathrm{nm})$ & $133.2 \pm 1.48$ & $160.2 \pm 3.20$ & $182.36 \pm 5.10$ \\
Zeta Potential $(\mathrm{mV})$ & $25.2 \pm 0.03$ & $13.7 \pm 0.24$ & $9.24 \pm 0.37$ \\
\% EE & $69.13 \pm 0.59$ & $63.78 \pm 0.87$ & $213.51 \pm 6.92$ \\
\hline
\end{tabular}

Results are presented as mean \pm SD $(n=3)$.

Table 10: ETB release profiles from optimized formulation (F11) during the stability studies (before and after storage) at (40 \pm 2 $\left.{ }^{\circ} \mathrm{C} / 75 \pm 5 \% \mathrm{RH}\right)$

\begin{tabular}{|c|c|c|c|}
\hline \multirow[t]{3}{*}{ Time (h) } & \multicolumn{3}{|l|}{$\%$ CDR } \\
\hline & \multirow[t]{2}{*}{ Before storage } & \multicolumn{2}{|c|}{ After storage } \\
\hline & & 3 Mo & $6 \mathrm{Mo}$ \\
\hline 0 & 0 & 0 & 0 \\
\hline 0.25 & $8.32 \pm 0.01$ & $10.45 \pm 0.04$ & $10.24 \pm 0.23$ \\
\hline 0.5 & $15.91 \pm 0.23$ & $17.12 \pm 0.05$ & $16.25 \pm 0.01$ \\
\hline 0.75 & $19.10 \pm 0.14$ & $21.23 \pm 0.42$ & $22.35 \pm 0.25$ \\
\hline 1 & $23.26 \pm 0.25$ & $25.21 \pm 0.03$ & $23.25 \pm 0.56$ \\
\hline 1.5 & $29.38 \pm 0.24$ & $29.56 \pm 0.23$ & $31.38 \pm 0.45$ \\
\hline 2 & $35.50 \pm 0.26$ & $37.56 \pm 0.25$ & $34.50 \pm 0.78$ \\
\hline 3 & $39.23 \pm 0.25$ & $41.20 \pm 0.24$ & $36.23 \pm 0.69$ \\
\hline 4 & $45.54 \pm 0.24$ & $47.28 \pm 0.02$ & $42.64 \pm 0.45$ \\
\hline 5 & $48.72 \pm 0.63$ & $52.14 \pm 0.36$ & $49.72 \pm 0.36$ \\
\hline 6 & $51.90 \pm 0.85$ & $54.96 \pm 0.56$ & $53.90 \pm 0.24$ \\
\hline 7 & $57.78 \pm 0.24$ & $59.54 \pm 0.45$ & $57.78 \pm 0.26$ \\
\hline 8 & $59.98 \pm 0.12$ & $61.24 \pm 0.36$ & $59.98 \pm 0.27$ \\
\hline 9 & $61.94 \pm 0.23$ & $64.25 \pm 0.25$ & $66.94 \pm 0.36$ \\
\hline 10 & $68.06 \pm 0.23$ & $66.64 \pm 0.24$ & $71.06 \pm 0.45$ \\
\hline 11 & $73.20 \pm 0.24$ & $69.47 \pm 0.36$ & $73.20 \pm 0.78$ \\
\hline 12 & $75.90 \pm 0.26$ & $73.52 \pm 0.54$ & $76.90 \pm 0.64$ \\
\hline 24 & $77.12 \pm 0.36$ & $75.70 \pm 0.68$ & $78.12 \pm 0.32$ \\
\hline
\end{tabular}

Results are presented as mean \pm SD $(n=3)$ 
The optimized batch of polymeric nanoparticles of ETB was charged on accelerated stability and monitored for particle size, zeta potential, entrapment efficiency, and in vitro dissolution profile studies at $40 \pm 2{ }^{\circ} \mathrm{C} / 75 \pm 5 \% \mathrm{RH}$ for 6 mo (table 9 and table 10 ). Characteristic parameters of Polymeric nanoparticles like particle size, zeta potential and entrapment efficiency conducted for 6 mo of storage had shown that there were no significant changes during the storage. The stability was evaluated based on the measurement of particle size, zeta potential, and entrapment efficiency at an interval of $30 \mathrm{~d}$ for $3 \mathrm{mo}$. It was found that the formulation was stable for two months as no significant change in particle size and entrapment efficiency was observed. However, the particle size increased from $133 \mathrm{~nm}$ to $213 \mathrm{~nm}$ at the end of $3 \mathrm{mo}$.

\section{CONCLUSION}

The Ethambutol loaded polymeric nanoparticles were formulated by the double-emulsion $(\mathrm{W} / \mathrm{O} / \mathrm{W})$ solvent evaporation/diffusion technique and found to be compatible between drug and other excipients within polymeric nanoparticles. Among the 16 formulations, F11 which was prepared using ETB (100 mg), Eudragit RS-100 (200 mg), poloxamer ( $1 \% \mathrm{w} / \mathrm{v})$ showed the smallest particle size $(136.1 \mathrm{~nm})$, better entrapment efficiency $(73.3 \%)$, good drug loading capacity $(13.21 \%)$ and zeta potential $(25.2 \mathrm{mV})$ with \% cumulative drug release of $79.08 \%$ at the end of $24 \mathrm{~h}$ was selected as the optimized formulation. The optimized batch was found to be stable for $90 \mathrm{~d}$. Thus, a once-a-day polymeric nanoparticle-based controlled drug delivery system of Ethambutol can be developed for a better therapeutic effect in the treatment of tuberculosis.

\section{ACKNOWLEDGMENT}

Authors are thankful to Mr. Sanjoy Das, Research Scholar, Department of Pharmaceutical Sciences, Dibrugarh University for kind help during manuscript drafting and revision.

\section{FUNDING}

Nil

\section{AUTHORS CONTRIBUTIONS}

All the authors have contributed equally.

\section{CONFLICT OF INTERESTS}

The authors declare that they have no conflict of interest.

\section{REFERENCES}

1. Gebrekristos HT, Lurie MN, Mthethwa N, Karim QA. Disclosure of HIV status: experiences of patients enrolled in an integrated TB and HAART pilot program in South Africa. Afr J AIDS Res 2009;8:1-6.

2. Golden MP, Vikram HR. Extra pulmonary tuberculosis: an overview. Am Fam Physician 2005;72:1761-8.

3. Jessy Shaji, Mahmood Sheikh. Formulation, optimization, and characterization of biocompatible inhalable D-Cycloserineloaded alginate-chitosan nanoparticles for pulmonary drug delivery. Asian J Pharm Clin Res 2016;9:82-95.

4. Shegokar R, Al Shaal L, Mitri K. Present status of nanoparticle research for treatment of tuberculosis. J Pharm Sci 2011;14:100-16.

5. Joshi JM. Tuberculosis chemotherapy in the 21 century: back to the basics. Lung India 2011;28:193-200.

6. Mitchison D, Davies G. The chemotherapy of tuberculosis: Past, present, and future. Int J Tuberc Lung Dis 2012;16:724-32.

7. Prabhu C, Jalihal, Vaibhav Rajoriya, Varsha Kashaw. Design, synthesis, and evaluation of new derivative of 1,2,4-Triazole for antimicrobial and anti-inflammatory activity. Int J Curr Pharm Res 2018;10:29-35.

8. Choudhary S, V Kusum Devi. Potential of nanotechnology as a delivery platform against tuberculosis. Curr Res Rev 2015;202:65-75.

9. Espinal MA, Kim SJ, Suarez PG, Kam KM, Khomenko AG, Migliori $\mathrm{GB}$, et al. Standard short-course chemotherapy for drugresistant tuberculosis: treatment outcomes in 6 countries. JAMA 2000;283:2537-45.
10. Bangun $H$, Tandiono S, Arianto A. Preparation and evaluation of chitosan-tripolyphosphate nanoparticles suspension as an antibacterial agent. J Appl Pharm Sci 2018;8:147-56.

11. Pal SL, Jana U, Manna PK, Mohanta GP, Manavalan R. Nanoparticle: an overview of preparation and characterization. J Appl Pharm Sci 2011;1:228-34.

12. Jessy Shajia, Mahmood Shaikha. Drug-resistant tuberculosis: recent approach in polymer based nanomedicine. Int J Pharm Pharm Sci 2016;8:1-6.

13. Mohammad Nasiruddin, Md. Kausar Neyaz, Shilpi Das. Nanotechnology-based approach in tuberculosis treatment; 2017. p. 1-12.

14. Praveen Sivadasu, Gowda DV, Siddaramaiah H, Hemalatha H. Ziprasidone hydrochloride loaded nanostructured lipid carriers (NLCs) for intranasal delivery: optimization and in vivo studies. Int J Appl Pharm 2020;12:31-41.

15. Nagavarma BVN, Yadav H, Ayaz A, Vasudha LS, Shivakumar HG. Different techniques for preparation of polymeric nanoparticles-a review. Asian J Pharm Clin Res 2012;5:16-23.

16. Iqbal M, Zafar N, Fessi H, Elaissari A. Double emulsion solvent evaporation techniques used for drug encapsulation. Int J Pharm 2015;496:173-90.

17. Yu X, Trase I, Ren M, Duval K, Guo X, Chen Z. Design of nanoparticle-based carriers for targeted drug delivery. J Nanomater 2016. Doi:10.1155/2016/1087250

18. Jiang J, Oberdorster G, Biswas P. Characterization of size, surface charge, and agglomeration state of nanoparticle dispersions for toxicological studies. J Nanopart Res 2009;11:77-89.

19. Mourdikoudis S, Pallares RM, Thanh NTK. Characterization techniques for nanoparticles: Comparison and complementarity upon studying nanoparticle properties. Nanoscale 2018;10:12871-934.

20. Chaurasia G. A review on pharmaceutical preformulation studies in formulation and development of new drug molecules. Int J Pharm Sci Res 2016;7:2313-20.

21. Kotila OA, Olaniyi OO, Adegoke AO, Babalola CP. Experimental determination of the physicochemical properties of lumefantrine. Afr J Med Sci 2013;42:209-14.

22. Indian Pharmacopoeia. Vol. 1. Indian Pharmacopoeia Commission; 2010.

23. Rao JP, Geckeler KE. Polymer nanoparticles: Preparation techniques and size-control parameters. Prog Polym Sci 2011;36:887-913.

24. Kumari A, Yadav SK, Yadav SC. Biodegradable polymeric nanoparticles based drug delivery systems. Colloids Surf B 2010;75:1-18.

25. Lee YS, Johnson PJ, Robbins PT, Bridson RH. Production of nanoparticles-in-microparticles by a double emulsion method: a comprehensive study. Eur J Pharm Biopharm 2013;83:168-73.

26. Ravi Kumar MN. Nano and microparticles as controlled drug delivery devices. J Pharm Sci 2000;3:234-58.

27. Song X, Zhao Y, Hou S, Xu F, Zhao R, He J, et al. Dual agents loaded PLGA nanoparticles: systematic study of particle size and drug entrapment efficiency. Eur J Pharm Biopharm 2008;69:445-53.

28. Saikia C, Hussain A, Ramteke A, Sharma HK, Maji TK. Cross linked thiolated starch coated Fe304 magnetic nanoparticles: Effect of montmorillonite and cross-linking density on drug delivery properties. Starch-Starke 2014;66:760-71.

29. Das S, Das MK. Synthesis and characterization of thiolated jackfruit seed starch as a colonic drug delivery carrier. Int J Appl Pharm 2019;11:53-62.

30. Kandav G, Bhatt DC, Jindal DK. Formulation and evaluation of allopurinol loaded chitosan nanoparticles. Int J Appl Pharm 2019;11:49-52.

31. Khaira R, Sharma J, Saini V. Development and characterization of nanoparticles for the delivery of gemcitabine hydrochloride. Sci World J 2014. Doi:10.1155/2014/560962

32. Tripathi A, Gupta R, Saraf SA. PLGA nanoparticles of antitubercular drug: drug loading and release studies of a waterinsoluble drug. Int J Pharmtech Res 2010;2:2116-23.

33. Bohrey S, Chourasiya V, Pandey A. Polymeric nanoparticles containing diazepam: preparation, optimization, 
characterization, in vitro drug release and release kinetic study Nano Converg 2016;3:3-9.

34. D'Souza S. A review of in vitro drug release test methods for nano-sized dosage forms. Adv Pharm 2014;304757:1-12.

35. Chourasiya V, Bohrey S, Pandey A. Formulation, optimization, characterization and in vitro drug release kinetics of atenolol loaded PLGA nanoparticles using 33 factorial design for oral delivery. Mater Discovery 2016;5:1-13.

36. Singhvi G, Singh M. Review: In vitro drug release characterization models. Int J Pharm Sci Studies Res 2011;2:77-84.

37. Muthu MS, Muthu S. Pharmaceutical stability aspects of nanomedicines. Nanomedicine 2009;4:857-60.

38. Sharma D, Maheshwari D, Philip G. Formulation and optimization of polymeric nanoparticles for intranasal delivery of lorazepam using box-behnken design: in vitro and in vivo evaluation. Biomed Res Int 2014;156010:1-14.

39. Mona Qushwy, Ali Nasr. Solid lipid nanoparticles as nano drug delivery carriers: preparation, characterization and application. Int J Appl Pharm 2020;12:1-9.

40. Indian Pharmacopoeia; 1996.

41. https://pubchem.ncbi.nlm.nih.gov/source/hsdb/3078. [Last accessed on 10 Dec 2019]

42. https://pubchem.ncbi.nlm.nih.gov/source/hsdb/3078\#section= Other-ExperimentalProperties. [Last accessed on 10 Dec 2019]

43. Christopher J Ferguson. An effect size primer: a guide for clinicians and researchers. Professional Psychol: Res Practice 2009;40:532-8.

44. https://pubchem.ncbi.nlm.nih.gov/compound/14052\#section= Other-Experimental-Properties [Last accessed on 10 Dec 2019]

45. JN Ravi Varma, T Santosh Kumar, B Prasanthi, J Vijaya Ratna. Formulation and characterization of pyrazinamide polymeric nanoparticles for pulmonary tuberculosis: efficiency for alveolar macrophage targeting. Indian J Pharm Sci 2015;77:258-66.

46. Yi Yan Yang, Tai-Shung Chung, Ngee Ping Ng. Morphology, drug distribution, and in vitro release profiles of biodegradable polymeric microspheres containing protein fabricated by double-emulsion solvent extraction/evaporation method. Biomaterials 2001;22:231-41.

47. Navneet Sharma, Parshotam Madan, Senshang Lin. Effect of process and formulation variables on the preparation of parenteral paclitaxel-loaded biodegradable polymeric nanoparticles: a co-surfactant study. Asian J Pharm Sci 2016;11:404-16.

48. Deepak Sharma. Formulation and optimization of polymeric nanoparticles for intranasal delivery of lorazepam using box- behnken design: in vitro and in vivo evaluation. BioMed Res Int 2014. https://doi.org/10.1155/2014/156010

49. H Chikaura. Effect of particle size on biological response by human monocyte-derived macrophages. Biosurface Biotribol 2016;2:18-25

50. Lisbeth Ilium, SS Davis, CG Wilson, NW Thomas, M Frier, JG Hardy. Blood clearance and organ deposition of intravenously administered colloidal particles. The effects of particle size, nature and shape. Int J Pharm 1982;12:135-46.

51. Pimchanok Witayaudom, Utai Klinkesorn. Effect of surfactant concentration and solidification temperature on the characteristics and stability of nanostructured lipid carrier (NLC) prepared from rambutan (Nephelium lappaceum L.) kernel fat. J Colloid Interface Sci 2017;505:1082-92.

52. Yuta Nakatuka, Hideto Yoshida, Kunihiro Fukui, Mitsuharu Matuzawa. The effect of particle size distribution on effective zeta-potential by use of the sedimentation method. Adv Powder Technol 2015;26:650-6.

53. Karim S Shalaby. Determination of factors controlling the particle size and entrapment efficiency of noscapine in PEG/PLA nanoparticles using artificial neural networks. Int J Nanomed 2014;9:4953-64.

54. Y Dastagiri Reddy, D Dhachinamoorthi, KB Chandra Sekhar Formulation and in vitro evaluation of antineoplastic drug loaded nanoparticles as drug delivery system. Afr J Pharm Pharmacol 2013;7:1592-604

55. DV Gowda, Vishnu Datta M, Meenakshi S, Siddaramaiah H, Vishal Kumar Gupta N. Formulation and evaluation of dry powders containing anti tuberculosis drugs for pulmonary delivery. Indo Am J Pharm Res 2013;3:1239-48.

56. Devina Verma. Design expert assisted nanoformulation design for co-delivery of topotecan and thymoquinone: optimization in vitro characterization and stability assessment. J Mol Liquids 2017;242:382-94.

57. Pedro Fonte. Effect of cryoprotectants on the porosity and stability of insulin-loaded PLGA nanoparticles after freezedrying. Biomatter 2012;2:329-39.

58. Dustin L Cooper, Sam Harirforoosh. Design and optimization of PLGA-based diclofenac loaded nanoparticles. PLOS One 2014;9:e87326

59. Suvakanta Dash, Padala Narasimha Murthy, Lilakanta Nath, Prasanta Chowdhury. Kinetic modeling on drug release from controlled drug delivery systems. Acta Poloniae Pharm Drug Res 2010;67:217-23.

60. Stability testing of new drug substances and products Q1A (R2). ICH harmonised tripartite guideline; 2013. 